\title{
VI. Das Gedicht und seine Quellen.
}

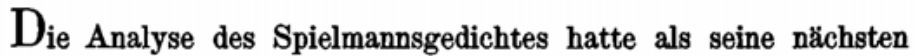
Quellen zwei selbständige und bedeutende epische Dichtungen von Orendel ergeben, denen wir uns jetzt wieder zuwenden.

\section{A. Die erste Quelle.}

Die Umrisse derselben mlissen noch einmal kurz vorgefuhrt werden. König Orendel auf einer Fahrt nach dem Osten begriffen leidet in Folge eines Seesturmes Schiff bruch und rettet sich allein, nackt an eine Diele geklammert, an ein einsames Gestade, wo er sich in den Sand gräbt, um nicht dem wilden Gevögel zur Beute zu werden. Einen voruberfahrenden Fischer Namens Ise ruft er um Hilfe an and die Scham mit einem Zweige deckend wird er von Diesem mitleidig aufgenommen, erhält einen Rock zum Geschenk and verdingt sich dafür als Fischerknecht. Als seine Zeit abgelaufen ist, beschenkt ihn Ise mit Ross und Schild und weist ihm den Weg. In seinem unscheinbaren Rocke kehrt Orendel in die Heimat zurück, wo er sein Weib von Freiern umworben findet, die er einzeln erschlägt. Wol ahnt sie in dem heldenhaften Fremdling den Gatten, doch er gibt sich ihr nicht zu erkennen, erst als er alle Gegner niedergeworfen, ihre Treue wiederholt die Prufung bestanden and sie ihm selbst mit dem Schwerte gegen die eignen Mannen zu Hilfe eilt, gibt er sich als Herr und König zu erkennen, dem Alles aufs Neue huldigt. Im Besitz seiner alten Rechte erinnert er sich dankbar des hilfreichen Fischers Ise und lässt ihn rufen, der in seinem grauen Rocke kommt, zwischen den Augenbrauen zwei Spannen breit. Ise empfängt einen kostbaren Mantel, ein Ross und einen Schild gefullt mit Gold zum Lohne und kehrt befriedigt nach Haus zurlick.

Damit ist der Mythus umgestaltet zu einer Heldensage fest in sich gegründet und von schöner Abrundung. Auch die Fahrt 
nach dem Osten wird hier, wie in den oben genannten Heimkehrsagen eine Motivierung gehabt haben, die unter den Händen des Bearbeiters natürlich verloren gehen musste, weil eine andere (die Brantfahrt) 2n ihre Stelle trat. Möglich auch, dass die Erkennung Orendels wie in verwanten Erzählungen durch ein bestimmtes Merkmal erfolgte: auch das hätte der Spielmann unterdrücken müssen, da es sich bei ihm ja nicht um ein Widererkennen handelte.

Wie die voraufgehende Untersuchung ergab, waren es drei mythische Zilge, die der Orendeldichter verarbeitete: die Knechtschaft bei Ise, die Rückkehr in niedriger Tracht, die Tötung des Buhlen. Nun sind aber die Riesen germanisch nirgends als Fischer zu belegen, eine Ausnahme bildet allein Hymir, der aber lediglich deshalb zum Fischer gemacht ist, um den Kampf Thors mit der Mitgardschlange zu ermöglichen.*) Auch Ise war ursprünglich kein Fischer: wie sein Fischertum in die Dichtung kam wird sich gleich zeigen. Was für Knechtsdienste hat aber Orendel dann geleistet? Die Antwort darauf gibt eine höchst eigentümliche Episode des Spielmannsgedichtes (V. $2997 \mathrm{ff}$ ), nach welcher Ise am Strande unbändige Rosse jagt: die riesische Schilderung Ises verrät das hohe Altertum dieser Stelle, die hier offenbar nicht an ihrem richtigen Platze steht. Wie wir oben nachweisen konnten, hat nach dem alten Gedichte Orendel Ross und Schild zugleich mit dem Rock von Ise erhalten: dahin gehört ursprünglich auch jene Scene, Ise fängt für Orendel das Ross am Strande ein. Der Überarbeiter, der die Situation spaltete, indem er Ross und Schild dem Helden erst durch Merzian zu Teil werden liess, konnte hier diese Scene nicht brauchen. Wie er aber im Gefühl des eigenen dichterischen Unvermögens von seiner Vorlage die charakteristischen Züge nach Krăften zu retten suchte, so hat er auch diese Scene später noch zu verwenden gesucht und $\mathrm{ihr}$ einstweilen seine Darstellung, wie Orendel das Ross Merzians erhält, nachgebildet: denn wie dort V. $3002 \mathrm{ff}$. ist auch Merzians Ross von unbändiger Natur, und wie dort die Folen plötzlich ihre Wildheit ablegen, sich beschlagen lassen und sich gebahren, als seien sie gezähmt (V. $3067 \mathrm{ff}$.), so ist auch hier das vorher so unbändige Ross dem Helden auf einmal zu Willen, wie ein sanftes Lämmlein. An dieser Scene wird Ises eigentliche Bedeutung klar: als Viehhirten lassen sich die Riesen widerholt nachweisen (vgl. den eddischen Thrymr, die wilde Jagd u. A.), ${ }^{* *}$ ) Orendel hat also Ise ursprünglich Hirtendienste geleistet.

*) Ueberzengend wird das dargelegt von Beer a. a. O. S. 33.

**) Der mythenbildenden Phantasie erscheinen die Wolken als Heerden: der Rossfang Ises wird demnach im letzten Grunde als eine Wolkenvorstellung aufzufassen sein (vgl. Beer, a. a. O. S. $112 \mathrm{f}$. 
Woher stammt nun das Fischertum Ises?

Dieses Fischertum hängt eng zusammen mit dem Schiffbruch Orendels. Schiff brüche gehören aber nicht in den Vorstellungskreis eines Binnenvolkes: wo sie in der deutschcn Litteratur anftreten, werden sie sich stets als Entlehnung aus griechischen, morgenländischen oder nordischen Sagenkreisen nachweisen lassen. Ganz ähnliche Schiff brüche erzählt die Kaiserchronik in der Geschichte des Faustinian. Dessen beide Söhne werden auf Reisen geschickt zu fernen Lehrmeistern; ein Sturm schlägt die Schiffe in den Grund, nur die beiden Jünglinge retten sich an einen Felsenstrand, wo sie ein Fischer in seinem Netze fängt, der sie dann auf dem Markte an eine Witwe verkauft (vgl. Kchr. D. 44, 18 ff.). Die Mutter, besorgt um ihrer Söhne Schicksal, reist ihnen nach, leidet aber ebenfalls Schiffbruch und rettet sich allein an das Gestade; dort kommt sie in eine Stadt, wo sie einer Witwe mehr als 13 Jahre dient (Kchr. D. 49, $7 \mathrm{ff}$ ). Der Kaiser, ihrer Rückkunft vergeblich harrend, entschliesst sich gleichfalls zur Reise, doch auch seine Schiffe gehen unter, er allein erfasst ein Bret und treibt damit an das Land, wo er nackt drei Tage lang ohne Nahrung umherstreift, bis er auf dem Meere einen Eseler fahren sieht, den er anruft, sich fur einen gescheiterten Kanfmann ausgebend. Der Eseler schenkt ihm sein Gewand und weist ihn in eine nahe Stadt, wo er in niederen Dienstleistungen sein Leben fristet. (Kchr. D. 52, 18 ff.).

Als die mittelbare Quelle dieser Erzählung sind die weitverbreiteten Clementinischen Recognitionen in der Übersetzung des Rufinus von Aquileja nachgewiesen (Massmann, Kchr. III, 642 ff). Das führt nach jener Richtung, in der wir auch die Quelle unseres Gedichtes zu suchen haben. Die "Recognitiones" sind bekanntlich der erste Versuch einer christlich-theologischen Verarbeitung der erotisch-sophistischen Romanschablone. Und Schiffbrïche mit wunderbaren Rettungen gehörten von jeher zu dem festen Inventar des griechischen Abenteuerromans. In der Tat findet sich auch Orendels Schiff bruch und die daran sich schliessende Handlung Zug um Zug in einem sophistischen Romane wieder, und zwar in demjenigen, der im Mittelalter vor allen anderen unumschränkte Verbreitung genoss, in dem Apollonius von Tyrus.

ther die auf das ganze Abendland sich erstreckende Geltung dieses an wechselvollen und spannenden Abenteuern so reichen, wenn auch poetisch ziemlich wertlosen Romans ist wiederholt gehandelt worden. Für uns genügt hier der Hinweis, dass er in Deutschland bereits im neunten Jahrhundert bekannt war (vgl. Haupt. Opuscula II, 1, 22). Eine bruchstückweise erhaltene angelsächsische 
Uebersetzung wird von einigen Gelehrten noch in das 10. Jahrhundert gesetzt.

Die für uns in Betracht kommende Stelle findet sich im 12. bis 14. Capitel dieses Romans (vgl. Riese, Historia Apoll. Regis Tyri Lipsiae 1871. pag. 15 sqq.). Apollonius flüchtet aus Tarsus vor den Nachstellungen des Antiochus nach der cyrenäischen Pentapolis. Auf dem Meere überfallt ihn ein furchtbares Unwetter: alle seine Gefährten versinken in den Wellen, er allein rettet sich auf einer Planke an die Küste, wo er sein trauriges Geschick beklagt und den trügerischen Neptun mit harten Worten schilt. Darauf sieht er einen alten Fischer in einem groben Mantel daherkommen. Diesem fällt er zu Füssen, gibt sich zu erkennen und ruft weinend sein Erbarmen für den nackten Schiff brüchigen an. Der mitleidige Fischer führt ihn in seine Hütte und teilt sein dürftiges Mahl mit ihm, dann zerreisst er sein Gewand in der Mitte und gibt ihm die Hälfte seine Blösse zu decken. Darauf weist er ihm den Weg in die Stadt: wenn er dort kein besseres Unterkommen finde, solle er nur wiederkommen und ihm fischen helfen; wenn er aber einst wieder zu Ehren komme, möchte er seiner nicht vergessen. In der Stadt angelangt, sieht Apollonius einen Knaben durch die Strassen laufen, der Fremde und Einheimische zum Gymnasium ruft. Er folgt der Aufforderung und findet daselbst den König Archistrates mit seinem Gefolge beim Ballspiel. Da weiss er so kunstvoll den Ball zurückzuschlagen und dem Könige so geschickt bei dem Bade zu dienen, dass er Dessen ganze Gunst gewinnt und zur Tafel geladen wird. Durch seine Kraft und Schönheit, durch die Kunst seines Saitenspiels erwirbt er die Liebe der Königstochter und erhält später ihre Hand. Als er nach mannigfachen Abenteuern schliesslich auch des Herrschertrones wieder teilhaftig wird, bescheidet er (cap. LI) auch den Fischer zu sich und belohnt ihn furstlich.

Die Quellen des Apolloniusromanes sind bisher nicht genlugend erforscht. Dass der Verfasser desselben die Scene am Beginn des Gastmahls bei König Archistrates (Riese pag. 18, 5 sqq.) dem Gastmahl des Menelaus in der Odyssee IV, 71 ff. nachgebildet habe, ist von anderer Seite bemerkt worden (vgl. Erwin Rohde, D. griech. Roman, S. 416). Ich glaube, dass auch zu der eben geschilderten Scene die Odyssee ihm die hauptsächlichsten Züge geliehen hat. Als Odysseus von Kalypso entlassen ist, bricht ein stürmisches Unwetter aus, das ihm kurz vor der phäakischen Küste das Schiff zertrümmert. Er schwingt sich auf einen Balken und erreicht mit Hilfe von Inos Binde das Land, wo er sich in aufgehäuftem Laube ein Bett bereitet. Durch das lärmende Ballspiel der Nausikaa und 
ihrer Gespielinnen aus dem Schlafe geweckt bricht er einen Zweig vom Gehölz, und die Scham damit bedeckend bittet er das Mädchen um ein Gewand, das ihm zugleich mit Trank und Speise gewährt wird. Darauf folgt er ihr in die Stadt zum Palast des Alkinous, wo man ihm ein Mahl rüstet.

Die Übereinstimmung mit dem Roman ist unverkennbar: nur für die Ballspielscene ist dort ein anderes Motiv eingetreten, weil sie verschoben und etwas anders gewant werden musste, damit Apollonius die Aufmerksamkeit des Königs auf sich ziehe. Allein zwei merkwürdige Züge hat der Roman nicht: das Einbetten im Laube und den Schamzweig, und diese beiden finden sich seltsamer Weise gerade im Orendel wieder: V. 500 gräbt Orendel mit den Händen ein Loch sich hineinzubetten und V. 548 bricht er einen Zweig die Scham damit zu bedecken. Das sind aber zwei Züge von so charakteristischer Eigenart, dass man nicht annehmen wird, sie seien nnabhängig von einander erfunden; wir müssen notwendig Entlehnung annehmen. Da nun die betreffende Stelle des Apolloniusromanes unter dem unleugbaren Einflusse der Odyssee steht, da andererseits der Orendel in jenen zwei eigentümlichen Zügen zur Odyssee stimmt, und da endlich der Apollonius an dieser Stelle durchaus dem Orendel entspricht (Schiffbruch, Versinken der Gefährten, Rettung auf einer Diele, Beklagen der Nacktheit, Anrufung des Fischers, Mantelspende, Weisung des Weges und später folgende Belohnung), so bleibt nur die Annahme übrig, dass der Roman jene beiden Züge fallen liess oder dass wenigstens die uns erhaltenen Bearbeitungen desselben sie unterdrückt haben. Nun ist es aber nach den Beobachtungen von Riese (Praef. XV sqq.) und Rohde (D. griech. Roman 414 ff.) höchst wahrscheinlich, dass die auf uns gekommene Gestalt des Romans nicht nur den ganzen Ton der Erzählungsweise verändert, sich manigfache Zusätze und Änderungen erlaubt, sondern auch das Original vielfach verkürzt hat (vgl. Riese p. XVI, n. 1. Rohde S. 417, Anmkg. 5). Solche Verkürzungen lassen sich aber von einer ganz anderen Seite her ganz bestimmt nachweisen, denn so kurz die gelegentliche Bemerkung ist, die Lamprecht im Alexander 1430 ff. über die Apolloniussage macht, so enthält sie doch zwei Züge, die der uns vorliegende Roman nicht kennt, nämlich dass Apollonius Tyrus wiedererbaut nnd dass er des Rätsels Lösung in einem Briefe gegeben habe. Dass Lamprecht seiner französischen Quelle das einfach nachgeredet hat, ohne in seinem Gedächtnis irgendwelchen Anhalt dafür zu haben, wird Niemand glaublich finden. Er hat aller Wahrscheinlichkeit nach eine vollständigere Fassung 
des Romanes gekannt, nnd der verkürzenden Bearbeitung, die auf uns gekommen ist, werden auch jene beiden Motive zum Opfer gefallen sein.

Je schärfer wir aber unser Gedicht ins Auge fassen, um so deutlicher tritt die Übereinstimmung mit dem Roman hervor. Nach V. 521 liegt Ises Behausung in einer öden Wildnis: warum Orendel befürchtet für einen Räuber und Dieb gehalten zu werden (V. 496) und warum ihn Ise, und später auch Dessen Frau, wirklich dafür hält (V. 524. 612), bleibt daher völlig unverständlich. Ebenso wenig liegt für Orendel irgendein Grund vor seinen Stand zu verheimlichen und sich für einen gescheiterten Fischer auszugeben. Der spielmännische Bearbeiter wusste freilich warum: um des wunderbaren Fischfanges willen. Im alten Gedichte aber, wo eine derartige legendarische Absicht fern lag, hat Orendel - das können wir mit Bestimmtheit behaupten - wie es sich gebührte, seinen Namen und seine Herkunft genannt, genau wie Apollonius, und mag Ise auch anfänglich dem nackten Fremdling nicht ganz getraut haben: als Orendel gerüstet zu Pferde sitzt und den Speer schwingt, da glaubt er ihm, er müsse wol ein Herzog sein (s. S. LXIX). Die Aehnlichkeit mit dem Roman wird indes noch überraschender. Als Ise an den Hof Orendels kommt, heisst es V. 2270: Sînen grâwen roc truog er an, und die wiederholt erwähnte Schilderung Ises als eines Riesen gleich darauf beweist, dass diese Stelle dem Original angehörte. Also auch Ise hat einen grauen Rock. Daraus dürfen wir aber im Hinblick auf die in jedem einzelnen Zuge hervortretende Aehnlichkeit der beiden Situationen den sicheren Schluss ziehen, dass in dem zu Grunde liegenden Gedichte, wie der Fischer dem Apollonius, so auch Ise dem Orendel die Hälfte seines Gewandes geschenkt habe. Ohne diese Annahme wäre V. 2270 einfach nicht zu verstehen. Diesen Zug hat aber der Ueberarbeiter bis auf die einzige Spur verwischt, weil er in seiner Sucht nach legendenhafter Ausschmückung, wie sich unten zeigen wird, über den Rock anders zu verfügen gedachte.

Mit dieser Einflechtung der Apolloniusgeschichte hat aber der Dichter dem Orendelmythus jenes veränderte Gepräge aufgedrückt, welches zu der unrichtigen Deutung Ises sowol wie Orendels den Anlass gegeben hat. Wir hatten drei mythische Züge ausgeschieden, die der Dichter des Orendel ineinander arbeitete, einmal: Orendels Knechtschaft im Osten bei Ise, ferner: die Rückkehr zu Bride und Bekämpfung des Buhlen, endlich: die dürftige Kleidung. Die letztere musste notwendig motiviert werden: er hat sie in der Knechtschaft erhalten. Dabei konnte denn leicht vor dem Dichter Apollonius von Tyrus auftauchen, der ja auch von einem Greise mit einem groben 
Kleide beschenkt wurde, als er fern von der Heimat war. Damit war die Anknüpfung gegeben, und in Folge dieser Sagenverschmelzung ging der Eisriese in den Fischer Ise über und Orendel wurde zum Seefahrer. ${ }^{*}$ )

Wenn es noch eines Beweises bedarf, dass das so weit verbreitete und beliebte Buch von Apollonius auch in Spielmannskreisen heimisch war, so lässt er sich leicht erbringen. In einem Abschnitt der Thidreksaga (Unger cap. 245 ff.) wird erzählt, dass die Söhne des König Artus von Bertangenland, Iron und Apollonius, nach dessen Tode vor den Eroberungen des Königs Isung fliehen müssen; sie kommen zum Hunnenkönig Attila, und Dieser macht Iron zum Jarl von Brandenburg, Apollonius zum Jarl von Tyra. Es folgt nun eine verworrene Reihe von Abenteuern, eine willkürliche Mischung heterogener Sagenbestandteile, die mit der Sage von Apollonius nicht das Geringste gemein haben. Dass dieser Name aber in eine ganz

*) Dabei mag auch der Name der Helden wesentlich mitgewirkt haben. Wie Müllenhoff (DA I, 34) nachweist, gab es ein altnord. aur, dem die Bedeutung des Feuchten innewohnte, und das ags. eár, das Müllenhoff mit grosser Wahrscheinlichkeit für dasselbe Wort erklarrt, bedeutet geradezu mare, oceanus. Dann wäre Aurvandil der „Seefahrer"; und gestützt wird diese Auffassung durch den mit ihm allitterierenden Namen seines Vaters in der deutschen Sage Ougel, den Müllenhoff a. a. O. S. 32 mit ouwa (mlat. augia, mhd.ouwe) zusammenbringt, was wieder auf die Bedeutung des Feuchten, Fliessenden führen würde. Beer glaubt deshalb, dass, als man aur in der Bedeutung "glanzen" nicht mehr gefühlt babe, aus dem "Glanzwandler" der "Flutenwandler" Aurvandil geworden sei. Im Zusammenhang mit dieser jüugeren Namensdeutung wäre dann die Fahrt nach dem Osten bereits als eine Seefahrt aufgefasst worden, was allerdings die Anknüpfung der Apolloniusgeschichte noch erleichtert haben würde. Die Morglichkeit dieser Annahme muss zugegeben werden. Freilich setzt die Form des Namens gerade bei Saxo, der doch den Seehelden am Entschiedensten betont, Horvendillus nicht ein Aurvandil, sondern das jüngere Örvandil voraus. Wie aber Namen die Sagenentwicklung beeinflussen kơnnen; das zeigt eine Ueberlieferung des 16. Jahrhunderts, die sich an den Namen Orendel knüpfte, und die bei dieser Gelegenheit erwahnt sei. Aus Widmanns Chronik der Stadt Hall teilte Pfeiffer (Zschr. f. d. A. VII, 558) eine Stelle mit, nach der in der Grafschaft Hohenlohe an der Saal ein frommer Waldbruder Namens Orendel lebte, zu dessen Grabe spater Viele wallfahrteten, die an den Ohren litten. Das noch heute bestehende Pfarrdorf Orendelsall bei Oehringen im würtembergischen Jaxtkreis ist zugleich die einzige Erinnerung, die in der Gegenwart noch auf den altgermanischen Helden zurückdentet, freilich erst vermittelt durch die Gestalt jenes frommen Einsiedlers. - Mit dem Nachweis der Einwirkung des Apolioniusromanes erledigt sich aber eine andere Vermutung Beers, welche das Fischertum Ises so erklärt, dass sich der Fischer an den Fuhrmann angeschlosseu habe, da wir Riesen als Fuhrmanner und die Wolke als Fahrzeug in nordischen Quellen belegt finden. Ebenso fallen damit die unsicher tastenden Bemerkungen von Heinzel im Anz. f. d. A. IX. 256 
fremde Sagengruppe hineingestreut ist, spricht wiederum für die Beliebtheit seiner Geschichte, und dass wir es in diesem Teile der nordischen Sage mit der sorglosen Arbeit eines echten und rechten Spielmanns zu tun haben, leuchtet Jedem auf den ersten Blick ein, ist auch wiederholt ausgesprochen worden (vgl. Müllenhoff, z. Gesch. d. Nib. Not S. 22. Haupt, Opuscula III, 1, 25).

Aus der Verflechtung der drei Mythen von Orendel mit der Apolloniussage ergab sich aber erst Zusammenhalt und Gliederung des Ganzen: fast die ganze Fabel liess sich aus dieser bestreiten. Selbständig hinzugefügt hat der Dichter nur wenige Züge. Der Fischer kommt nicht, wie im Roman, zu Fuss daher, sondern Orendel sieht ihn vorüberfahren. Da wird jedenfalls das Vorbild der Faustiniansage eingewirkt haben, welche ich oben S. XC nach der Kaiserchronik mitteilte: dort streift auch der Kaiser nach dem Schiffbruch, wie Orendel, drei Tage ohne Nahrung umher, bis er auf dem Meere einen Eseler fahren sieht, den er um Hilfe anruft. Eine weitere Veränderung ist, dass Orendel von Ise nicht nur die•Hälfte seines groben Gewandes, sondern auch Ross und Schild erbält, damit er sogleich den Kampf gegen die Freier aufnehmen könne. Deshalb lässt der Dichter auch Ise erst das Ross am Strande flir Orendel einfangen und rettete damit einen alten mythischen Zug, der zu dem von ihm geschaffenen Fischertum Ises eigentlich nicht passt. Nach dieser dreifachen Gabe musste dann auch am Schlusse die dreifache Ablohnung Ises mit Mantel, Ross und dem goldgefüllten Schilde eingerichtet werden (vgl. oben Seite LXX). Die eingreifendste Umgestaltung ist aber, dass der Dichter aus dem einen Buhlen der Gattin eine Menge von Freiern gemacht hat, und, wie schon oben angedeutet wurde, hat hier wahrscheinlich die Legende von der heiligen Brigida eingewirkt, daneben aber auch eine künstlerische Absicht, die am Deutlichsten aus einer Würdigung der von unserm Dichter gestalteten Charactere hervorgehen wird.

Bride ist die dichterische Verkörperung der hehrsten weiblichen Treue, der aufopfernden, todesmutigen Gattenliebe, eine Gestalt, an standhafter Kraft und Tiefe des Gefühls einer Gudrun ebenbürtig. Wir sehen sie mit ihren Jungfrauen auf der Zinne stehen, scheinbar teilnehmend an dem Spiel der um ihre Gunst wetteifernden Freier unten im Burghofe, in Wahrheit den Blick sehnend in die Ferne gerichtet nach dem so lange ausgebliebenen Gatten. Da erscheint plötzlich ein Fremdling in dürftiger Kleidung, verhöhnt von den Mannen, auf dem Platze und säet Entsetzen unter Jene, einen Freier nach dem andern niederstossend. Eine freudige Gewissheit leuchtet in ihr auf, sie sendet dem Unbekannten einen Boten, ihm ihre Minne zu entbieten. Er aber gibt sich für einen armen Waller aus und 
weist den Boten $a b$, der der Herrin meldet, der Graurock blicke zornig drein mit Wolfsblicken und sei von furchtbarer Gestalt. Die Freier neidisch auf die jenem Verhassten erwiesene Ehre, doch orschreckt durch die Gewalt seiner Waffentaten, rufen ihre mächtigsten Genossen, drei Riesen, zu Hilfe. Als Orendel den ersten mit seinem ganzen Anhang erschlagen hat, geht ihm Bride selbst entgegen, ruft ihn bei seinem Namen und klisst ihn. Er verleugnet sich abermals. Einer der Freier schilt die Fürstin, dass sie einen gemeinen Knecht küsse, doch gleich muss er den Frevel büssen, und Bride lässt ihn in den Kerker werfen. Als der zweite Riese heranzieht, reicht sie dem Gatten selbst ein wunderbares Schwert, das nie versagt, und Orendel bleibt abermals Sieger. Wie er in die Burg zurückkehrt, dringt sie auf's Neue vergeblich in ihn, ${ }^{*}$ ) dann bedient sie ihn mit den eignen Händen im Bade, kleidet ihn prächtig und will mit ihm das Lager teilen. Ihre Prüfung ist aber noch nicht zu Ende: er legt das Schwert zwischen sich und sie, wie ein Fremdling, der ihr Magdtum ehren will. Doch mit edlem Stolze gibt sie ihm zu ver. stehen: „Herr, stoss dein Schwert wieder ein, ich kann wol 10 Jahre deiner Minne entraten! ${ }^{*}$ Endlich erscheint der gewaltigste der riesischen Freier mit einem mächtigen Heerbann: Orendel überwindet anch diesen, aber allein scheint er der Ueberzahl preisgegeben, kein Einziger steht ihm bei. Da im Augenblicke der höchsten Gefahr eilt Bride auf den Kampfplatz, das eigene Leben einzusetzen für den geliebten Gatten. Da lässt der Fremdling die Maske fallen: die Gattin hat die Prüfung siegreich bestanden, er gibt sich den erschrockenen Mannen als Herr und König zu erkennen, und Alle huldigen ihm reumütig.

Dass die drei Riesenkämpfe dem alten Gedichte angehörten, ist bereits früher nachgewiesen worden; auch die hier ausgehobenen Züge, $\left.{ }^{* *}\right)$ die Einkerkerung des schmähsüchtigen Freiers, die Verleihung des Schwertes, das Bad, die Trennung der Gatten durch das Schwert und Brides Eingreifen in den Kampf hatten ihre eigentliche Bedeutung nur im alten Gedichte, einem Hohen Liede der weiblichen Treue, die der härtesten Prüfung unbeugsam Stand hält. Alles was hier von tiefem Sinn und grossartiger dichterischer Wir-

*) In den Versen $1778 \mathrm{f}$ : ir sollent warten eines küiniges zuo hand Der dô habe liut und land steckt eine feine Anspielung: der erwartete König ist ja Orendel selbst, doch Land und Leute will er sich erst zurück gewinnen.

**) Sie sind auch sonst haufig genug nachzuweisen, vgl. die Anmerkungen zu V. 1638. 1788. 1818. 
kung war, musste in dem Spielmannsgedichte, welches doch auf eine Brautfahrt hinausläuft, platt und unverständlich werden.*)

Orendel selbst vereinigt alle Eigenschaften eines echten Helden. Wie trostlos er über sein Schicksal ist, das ihm alle Gefährten raubte und ihn in hilfloser Nacktheit an ein ödes Gestade warf sobald er durch des Fischers Mitleid sich gerettet sieht, erwacht auch die Heldennatur auf's Neue in ihm: er verlangt Ross und Schild, der lang entbehrten Heimat zuzureiten. Ise fängt ihm am Strande ein Ross, dessen Unbändigkeit sich vor Orendels kräftiger Faust sogleich zitternd beugt; und wie er sich gleich einem gewaltigen Recken hinaufschwingt, da entlockt sein heldenhaftes Gebahren dem vorher noch misstrauischen Ise den bewundernden Ausruf: „Ja, du musst wirklich ein Herrscher sein!“ Seine wunderbare Tapferkeit wird der Schrecken der Freier und lässt die harrende Bride den königlichen Gatten in ihm erkennen. Daneben treten aber Züge eines weicheren Gemüthes hervor: wie demütig fleht er das Mitleid des Fischers an, wie edel ist seine Dankbarkeit, mit der er seinen Woltäter, dem er doch schon Knechtesdienste getan, belohnt! Als er erfahren hat, wie sein Weib und Heimwesen von Freiern umlagert ist und sieht dann die Gattin auf der Zinne stehen, wie sie dem Kampfspiel im Burghofe zuschaut, da bricht er in herzliches Weinen aus. Und als nach jedem Siege Bride von Neuem in ihn dringt, dass er den geliebten Namen nenne: wie rührend wirkt seine Entsagung, indem er sich bis zu dem Augenblicke, da er seiner Herrschaft wieder unbestrittene Geltung erkämpft hat, zu der harten Prüfung seines Weibes entschliesst, aus der aber ihre Liebe nur um so geläuterter und unüberwindlicher hervorgeht! Und wie er edelmütig ist, indem er einen Freier, der ihn einen gemeinen Knecht gescholten, von der durch Bride ihm bestimmten Strafe befreit, ja ihn sogar entschuldigt, weil er ihm den Bruder erschlagen, so ist er auch freigebig, wie es dem Fürsten ziemt: des Riesen kostbare Rüstung schenkt er grossmütig dem fahrenden Volke.

Auch in Ise, dem von seiner ursprünglichen Riesennatur noch wenige Zïge anhaften, hat der Dichter einen trefflichen Character geschaffen: wie er anfänglich dem Fremdling misstrauisch begegnet, wie aber seine Gutmütigkeit die Oberhand behält, sodass er seine geringe Habe mit ihm teilt, wie dann der Held durch sein ganzes Gebahren ihn gewinnt und überzeugt von der Wahrheit seiner Aus-

*) Nur eines dieser Motive, das Schwert im Brautbett, hat der Spielmann in seiner Weise zu begründen versucht, natürlich wider durch himmlisches Gebot V. $1805 \mathrm{ff}$. 
sage, dass er ein König sei, wie er schliesslich des fürstlichen Lohnes froh und aller Sorgen ledig zurückkehrt - das Alles kommt klar and anschaulich zur Erscheinung.

Dass sich in verschiedenen Scenen ein bedeutendes Individualisierungsvermögen zeigt, dass eine Reihe kräftiger und höchst anschaulicher, teilweise bumoristisch gefärbter Bilder den eigenartigen und hochbegabten Dichter verraten, ist bereits oben ausführlicher dargetan worden (S. LXXI f.).

Auch dies Gedicht ist offenbar aus Spielmannskreisen hervorgegangen. Wäre dies nicht schon an und für sich wahrscheinlich, so würde es aus der Schilderung der prachtvollen Rüstung des Riesen Mentwin (vgl. Anmkg. zu V. 973), sowie daraus deutlich hervorgehen, dass Orendel dessen Rüstung den Fahrenden schenkt, die sie jubelnd vertrinken und dass drei von den Freiern Riesen sind, von denen Einer sogar auf einem Elephanten reitet. Auch die Belohnung Ises mit Ross und Mantel erinnert an die Beschenkungen der Fahrenden. Ferner hat sich gewiss auch dies alte Gedicht typischer Reime bedient, denn Formeln wie frouuce Brîde: Die schoenste ob allen wîben, meister Îse: Ein vischer hêr und ûेse sind sicher nicht erst vom Ueberarbeiter geprägt worden. Für eine nähere Bestimmung der Abfassungszeit des Gedichtes gebricht aber leider jeder Anhalt.

\section{B. Die zweite Quelle.}

Wie ein fruherer Abschnitt nachwies, war der Inhalt dieses Gedichtes in Kürze folgender: Orendel kehrt nach langer Abwesenheit - und zwar vermutlich aus der Knechtschaft - zurück nach der Heimat in Pilgertracht und findet an seiner Burg einen greisen Pförtner, der für das Wol seines Herren und dessen bedrängter im Kerker schmachtenden Gattin betet. Und als ihn der treue Diener bittet, wenn er wieder über das Meer gehe, möchte er dem König Orendel Nachricht geben von Brides Schicksal, da gibt er sich ihm zu erkennen. Beide verabreden nun die List, dass der Pförtner Orendel für seinen Verwanten ausgebe und für ihn um freies Geleit bitte. Darauf folgte jene meisterhaft ausgefuhrte Scene, die oben S. LXXIV f. im Zusammenhang behandelt ist, Orendels Entdeckung und die Flucht des buhlerischen Königs in den Turm. Während nun der alte Burgwart die getreuen Mannen aufbietet und mit Orendels Hilfe die Anhänger des Usurpators besiegt, behütet Bride gewappnet die Turmpforte, dass Dieser nicht entrinne. Darauf tritt Orendel in seine alten Rechte ein, der Nebenbuhler wird erschlagen.

Während die Untersuchung des ersten Gedichtes durch die 
Einflechtung der Apolloniussage und anderer Züge erschwert wurde, liegt hier Alles klarer und einfacher. Aus dem Mythus stammen wiederum drei Motive: Orendels Abwesenheit in der Knechtschaft, seine Rückkehr in niederer Tracht und die.Erschlagung des Buhlen, der letztere Zug ursprünglich gegenüber dem ersten Gedichte, das mehrere Freier einführte. Aber noch ein Viertes ist beiden Dichtungen gemeinsam: Brides amazonenhaftes Eingreifen in den Kampf. $\mathrm{Da}$ aber beide Gedichte so verschieden in Aufbau und Anlage sind und jedes in seiner Art bedeutend, so kann diese Aehnlichkeit nicht auf Entlehnung des einen aus dem andern zurïckgefuhrt werden, vielmehr lag beiden Dichtern bereits eine selbständige Sage vor des Inhalts: Orendel kehrt nach langer Knechtschaft im Osten in die Heimat zurück, findet bei seiner Gattin einen Bublen und erschlägt ihn, mit ihrer Hilfe die Herrschaft zurückgewinnend.

Hier wie dort ist Bride das leuchtende Vorbild unentwegter Gattentreue; wie sie dort die drängenden Freier hinzuhalten weiss, der Riickkehr des Geliebten entgegenharrend, so erträgt sie hier die Qualen des Kerkers und der Geisselung nur von der Hoffnung auf den erlösenden Gemahl aufrechterhalten; hier wie dort endlich erkennt sie ihn in dem fremden Pilger und steht ihm im Kampfe gegen seine Feinde siegreich bei: der Character Brides war also bereits von der Sage geprägt. Während aber dem ersten Dichter der Character zur Hauptsache wurde, der bei ihm eine Reihe schwerer Prüfungen zu durchlaufen hat, um seine unbeugsame Grösse stets von Neuem zu bewähren, gipfelt bei dem zweiten Dichter Alles in der Situation, in der scharfen Zuspitzung des Conflictes, in dem spannenden Gegenüber unversöhnlicher Gegensätze. Wir haben es dort mit einem mehr epischen, hier mit einem echt dramatischen Talente zu tun.

Ein so kraftvolles Talent aber, das seinem Stoffe nur die dramatische Seite abzugewinnen strebt, nur die aus den gegebnen Characteren sich entwickelnden Gegensätze scharf herauszuarbeiten trachtet, kann am Ehesten des epischen Beiwerkes entraten. Es ist daher ganz natürlich, dass wir hier der Sage in ihrer einfachsten Form begegnen: nur zwei Gestalten hat der Dichter neu eingeführt, den getreuen Burgwart und den bösen Ratgeber (Princian). Der erstere ist aus einer Reihe von Heimkehrsagen bekannt; der zweite erinnert einerseits an die ungetreuen Ratgeber, wie sie die germanische Sage oft gestaltet hat, und als deren berühmtester Vertreter Sibich galt, andererseits an den Peiniger oder die Peinigerin aus dem Kreis der Hildensagen, in deren Hände die Tochter gegeben wird, bis sie ihr Jawort gibt.

Dass auch dieses Gedicht aus Spielmannskreisen hervorgegangen 
sei, dürfen wir unbedenklich annehmen, über seine Entstehungszeit lässt sich ebenfalls nichts Näheres vermuten.

\section{Der Anteil des Spielmannes.}

Damit wenden wir uns dem unerquicklichsten Teile unsrer Aufgabe zu. Die Leistung des spielmännischen Ueberarbeiters erschöpft sich in zwei Richtungen: er hat einerseits die Orendelsage mit der Legende vom heiligen grauen Rocke Christi zu verschmelzen gesucht, andrerseits den Stoff nach der ihm geläufigen Schablone zurechtgeschnitten.

Ueber die Geschichte des Rockes Christi sind wir durch die Untersuchungen von Gildemeister und v. Sybel (Der heilige Rock zu Trier u. s. w. Düsseldorf 1845) trefflich unterrichtet

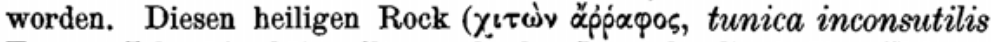
Evang. Joh. 19, 23) sollte nach der Legende die heilige Helena, welche in Trier geboren sein, daselbst gewohnt und Gebäude errichtet haben sollte, durch den Bischof Agröcius nach Trier gesant haben. Die Fabel, dass Trier die Heimat Helenas sei, taucht zuerst in der zweiten Hälfte des 9. Jahrhunderts auf bei dem Benedictiner Almanus von Hautvillers, die Legende in der eben erwähnten Gestalt aber erst fast drei Jahrhunderte später. Noch Abt Berengosus von St. Maximin, der uber Helenas Kreuzfindung im Anfang des 12. Jahrhdts. ein weitläufiges Buch schrieb und von ihrem Verhältnis zu Trier ausführlich darin handelte, gedenkt des Rockes mit keinem Worte. Und Abt Thiofrid von Echternach, der zwischen 1101-1106 ein Werk von der Verehrung der Reliquien verfasste, in dem er auch von dem heil. Rocke Christi eingehend spricht, weiss nur zu erzählen, dass derselbe in Safed gefunden und nach Jerusalem gebracht sei, und sein Buch ist dem Erzbischof Bruno von Trier (1101-1124) gewidmet! Bis 1106 gab es also für Trier keine officielle Tradition vom heiligen Rocke. Dem gegenüber lässt sich das Zeugnis der ältesten unter Bruno geschriebenen Redaction der "Gesta Trevirorum" als eine Fälschung nachweisen: in die Urkunde des Papstes Silvester vom Jahre 327, welche Trier den Primat über Gallien und Germanien zuerkennt und auch der dortigen Reliquien gedenkt, ist der graue Rock Christi zwischen 1106 und 1124 eingeschwärzt worden. Das Jahr der Fälschung lässt sich noch näher bestimmen. Im Jahre 1196 liess nämlich Erzbischof Johann die ihm wolbekannte Reliquie aus dem Nicolausaltar in den Hauptaltar des Domes uberführen. Der Nicolausaltar wurde aber im Jahre 1121 unter Bruno geweiht, hat also jedenfalls auch damals den grauen Rock in sich aufgenommen. Auf Bruno ist dem- 
nach die Fälschung zurückzuführen: er erhält den Rock, tauft ihn auf den Namen Christi und verwahrt ihn in dem 1121 gegründeten Nicolausaltar, gleich darauf wird die Reliquie auch in die Urkunde Sylvesters von dem Schreiber der Gesten eingeschwärzt. Freilich kam der Fälschung Brunos ein unbestimmtes Gerücht zu Hilfe: schon in der nach dem Jahre 1054 verfassten "Vita Agricii" wird angedeutet, dass im Dome sich eine nie eröffnete Kiste befinde, in der Einige den Rock Christi, Andere seinen Purpurmantel, Andere seine Schuhe vermuten. Man habe die Kiste einst erschliessen wollen, aber der Erste, der hineinsah, sei plötzlich erblindet, weshalb man von jedem weiteren Versuche abgesehen habe. Diesem Gerüchte fehlte die officielle Anerkennung, und Bruno verschaffte sie ihm. Nach dem Jahre 1196 wird des Rockes in keinem sicheren Zeugnis mehr gedacht, bis Kaiser Maximilian im Jahre 1512, wo es galt, den im tiefsten Grunde wankenden alten Glauben durch Wunder und frommen Betrug noch einmal. künstlich aufzurichten, die Ausstellung der Reliquie anordnete. Das gab den Anlass zur Veröffentlichung einer Reihe von Schriften, die sich mit dem Heiligtum beschäftigten; und diesem Ereignis danken wir auch Froschauers und Othmars Drucke des Orendel, die damit freilich den Germanisten des 19. Jahrhunderts einen weit grösseren Dienst erwiesen, als ihren Zeitgenossen. Wie nämlich unser Gedicht damals aufgenommen wurde, möge ein Beispiel zeigen. Johannes Enen in der "Medulla Gestorum Treuerensium " verspricht in der Dedication an den Kurfürsten Richard nur wirklich beglaubigte, ganz zuverlässige Nachrichten uber Trier und seine Heiligtümer geben zu wollen; bitter aber tadelt er die Bücher, die so vieles Entstellende und Falsche berichten, in besonderheit ein tractatel oder biichelin von einem kïnig genannt Orendel, welches doch gar falsch erdicht ond (alls ich glaub) vmb eigents nutz wille angefangen sey So es gar in keinen berïmbten angenommenden historiographen schrifften fonden wïrt.

Man muss dem frommen Manne Recht geben: der Spielmann, der die Legende vom heiligen Rocke mit der Orendelsage zusammenknüpfte, wird wol gewusst haben, warum er das tat. Wie im 16. Jahrhdt., so mochten auch im 12. schon allerlei Zweifel in Betreff der Trierer Tradition sich erheben: seit dem Jahre 1114 bereits hatte Mainz seinen heiligen Rock, 1156 taucht der heil. Rock zu Argenteuil auf, und einige Jahre später der römische Rock. Solchen Zweifeln suchte auch der Spielmann in seiner Weise zu begegnen, und ihm war es natürlich nicht um eine quellenmäässige Darstellung der beglaubigten Geschichte des Heiligtums, sondern lediglich um den klingenden Lohn zu tun; und zudem passte ja das 
Kokettieren mit geistlichem Aufputz zu seiner ganzen Gewöhnung, den Dichtungen der Geistlichen (wie später auch den höfischen) es möglichst gleichzutun, um aus dem Interesse des Publicums nicht durch jene verdrängt zu werden.

Den Anknüpfungspunkt für die Legende bot ihm der grave Rock, den Orendel von Ise erhält und in dem er unerkannt zurückkehrt. Damit es aber wirklich glaubwürdig erscheine, dass dies in der Tat der heil. Rock Christi gewesen sei, schickt der Spielmann erst eine lange Vorgeschichte dieser Reliquie voraus. Ob V. 1-18 von dem Verfasser des Ganzen herrührt oder jünger ist, lässt sich schwer entscheiden: die Verse sind eben auch nicht ungeschickter und plumper, als die folgenden, aber V. 19 sieht allerdings wie der Anfang des Gedichtes aus; vielleicht rühren sie von demselben Reimschmied her, der auch die oben S. LXV ausgeschiedene Interpolation V. $652 \mathrm{ff}$. auf dem Gewissen hat.

Es fängt gleich an mit einem echten Stück wirrer Spielmannsgelehrsamkeit. Der graue Rock stammt von eines schönen Lämmleins Haare, Maria spann ihn selbst, und Helena wirkte ihn auf dem Oelberge! Von diesem tollen Anachronismus hat natürlich der Spielmann nichts gemerkt; er weiss nur, dass Helena mit dem Rocke Christi in Verbindung gebracht wird und schmiedet daraus eine neue Tradition zurecht. Ebenso ist die folgende Geschichte eine leere Erfindung, die sich auf keine Ueberlieferung stützen konnte, weshalb sie auch in der Prosa sehr verkürzt erscheint. Nachdem Christus verraten, gekreuzigt und begraben ist, kommt ein Jude zu Herodes und bittet um Christi Rock als Belohnung für seine langen und treuen Dienste. Herodes gewährt ihm die Bitte. Das ist einfach eine aus dem Leben gegriffene Situation: der Fahrende, der um einen abgelegten Rock als Ablohnung bittet. Der Jude will nun den Rock waschen, aber die frischen Blutspuren lassen sich nicht entfernen (ein bekannter Legendenzug), da verbietet ihm Herodes, den Rock je wieder anzusehen: er muss ihn in einen Steinsarg verschliessen und in das Meer werfen. Nach drei Tagen treibt der Rock an einen Strand, wo ihn ein Engel aufhebt und neun Klafter unter der Erde verbirgt. So liegt er acht Jahre, bis er im neunten wieder an einem Gestade haftet, wo ihn der bekannte Waller Tragemund entdeckt. Als aber auch er das Blut nicht daraus zu tilgen vermag, erkennt er den heiligen Rock Christi, der keinem Sünder zu tragen zieme und wirft ihn wieder in das Meer, wo ihn ein Walfisch verschlingt. Bei einem glücklichen Fischzuge fängt dann Orendel den Wal, in dessen Magen Ise den Rock findet. Dieser Fischzug, wobei sich ein lange verloren geglaubter Gegenstand wiederfindet, ist bekanntlich eins der verbreitetsten Märchenmotive. 
Der graue Rock macht seinen Träger unverwundbar. Man hat deshalb wol angenommen, dass er auf ein Nothemd in der Sage zurückzuführen sei, es ist aber ein rein legendarischer Zug, der sich auch in anderen an den grauen Rock anknüpfenden Ueberlieferungen findet. So berichten v. Sybel und Gildemeister eine Sage, dass in Trier einst ein grausamer König lebte, der die geringsten Vergehen gleich mit Todesstrafe ahndete. Ein Soldat, der sich vergangen, klagt einem Juden sein Leid und erhält von Diesem den Rock, der ihn straflos macht. Der König muss ihn freisprechen und ebenso zwei Andere, die ebenfalls der Rock beschützt. Er forscht verwundert der Ursache nach und entdeckt die Reliquie. Eine andere Version der Legende erzählt, dass Kaiser Constantin uber Pilatus als den Urheber des Todes Christi die Todesstrafe verhängte, doch das Wunderkleid macht Diesen unverletzlich, sodass die Strafe nicht vollstreckt werden kann. Endlich verrät die heilige Veronica dem Kaiser das Geheimnis, Dieser bringt den Rock an sich, und die Bestrafung erfolgt.

Mit der Ueberführung des grauen Rockes nach Trier ist auch seine Geschichte zu Ende. Man sieht, der Spielmann hat sich eine eigene Legende vom Rocke Christi zurechtgemacht: aus der kirchlichen Tradition entlehnte er nur die unverletzlich machende Kraft desselben und den Namen der heiligen Helena, alles Uebrige setzt er aus bekannten, teilweise wiederholten Motiven zusammen.

Die Legende selbst ist mit der Orendelsage also nur locker und obenhin verknüpft, ein einheitliches Ganzes konnte sich so unmöglich gestalten lassen. Aber der Heldensage war damit ein fremdes Gewand umgehängt, und dies Gewand wurde dem Spielmann zur Hauptsache, von der der klingende Erfolg seiner Arbeit in erster Linie abhing. Wo also das dürftige Mäntelchen der Legende nicht reichte, um die Blössen des alten Gedichtes zu bedecken, da wurde eine geistliche Flicke nach der andern aufgesetzt, bis es leidlich gelungen war, dem Ganzen das Ansehen eines legendarischen Stoffes zu geben, nur ganz vereinzelt blickte noch die Hoheit der alten Heldenlieder durch.

Diese geistliche Flickarbeit muss im Zusammenhang betrachtet werden. Sie tritt einerseits in neuen Zügen hervor, mit denen die Handlung bereichert wird und die alle an dem gleichen Gepräge, der gleichen Tendenz kenntlich sind, andrerseits an Ruhepunkten der Erzählung in kurzen erbaulichen Betrachtungen, Gebeten und geistlichen Ausblicken.

Eine Reihe von Episoden dient nur dem Zwecke ein Wunder vorzuführen. Die typische Form dafür ist, dass Maria sich des in Verlegenheit geratenen Helden erbarmt und ihren Sohn bittet ihm 
beizustehen, worauf Christus ihm Hilfe sendet, meist durch einen oder mehrere Engel. So wird die Rettung aus dem Klebermeer V. $365 \mathrm{ff}$. vollzogen, welches der Dichter aber vermutlich nicht aus der Herzog-Ernst-Sage entnommen hat (vgl. Anmkg. zu V. 366): es war ja in Deutschland auch aus andern Quellen längst bekannt. Ebenfalls auf Marias Wunsch sendet dann Christus dem nackten Helden 30 Pfennige, dass er dafür den grauen Rock erstehe. Und hier schliessen sich gleich zwei neue Wunder an. Als der für den Rock geforderte Preis sich aus der himmlischen Geldspende nicht bestreiten lässt, reisst derselbe plötzlich wie faul auseinander, sodass er ihm für die 30 Pfennige überlassen wird: sobald ihn aber Orendel anlegt, erscheint er wieder nagelneu. Dies Motiv kehrt in Legenden nicht selten wieder, bestimmte Beispiele sind mir allerdings gegenwärtig nicht zur Hand. Ebenso ist die Begegnung mit dem Riesen und Orendels Einkerkerung V. $790 \mathrm{ff}$. nur um der himmlischen Befreiung willen eingeschoben. V. $997 \mathrm{ff}$. bringt der Engel Gabriel ein Paar goldene Schuhe, weil die groben Bundschuhe Orendels nicht in den Stegreif passen. Viermal wird der Graurock im Kampfe von den Erzengeln getröstet und unterstützt 1387 ff. 1662 ff. 2015 ff. 2792 ff. Endlich ist die Episode vom Zwerge Alban, der Bride durch einen hohlen Berg in Orendels Gefängnis führt, aber dann die Tür zuschlägt, weil sie ihm nicht zu Willen sein mochte, und der darauf von einem Engel blutig geschlagen wird, bis er Beide befreit, wieder nur um ihres wunderbaren Ausgangs willen erfunden. Alban mag aus Alberich der Reimbequemlichkeit halber gemacht sein, und dass Brides Minne begehrt wird kommt im Gedicht noch oft genug vor. Ob die eben angeführten Motive entlehnt sind oder aus des Spielmanns eigener Erfindung stammen, ist übrigens gleichgültig: nehmen wir auch das letztere an, so würde doch unser Urteil sich um nichts günstiger gestalten, denn Derartiges musste auch der dürftigsten Phantasie gelingen. Genug dass die Sucht nach Wundern überall hervortritt. Komisch genug wirkt die pathetische Aufforderung V. 2361 f., als Orendel im Kerker liegt: $N u$ râtent mit allen iuwern sinnen Wie wir in von dannen bringen (vgl. V. 375 f. 2476 f.). Die Antwort wird dem damaligen Publicum nicht schwerer geworden sein, als uns heute: die Hauptsache dabei war ja nur, dass der Spielmann einen Augenblick Zeit gewann die trockene Kehle zu netzen.

Auch sonst ist an Engelerscheinungen kein Mangel: drei Mal wird den Gatten untersagt der Minne zu pflegen $1803 \mathrm{ff}$. $2844 \mathrm{ff}$. (wo die Prosa, um auf das fromme Paar kein unlauteres Licht zu werfen, beifugt, dass die vorgeschriebenen 9 Jahre der Enthaltsamkeit abgelaufen wären) 3868 ff. Der Engel, der Triers Belagerung 
angezeigt hat, befiehlt auch V. $3162 \mathrm{ff}$. den heiligen Rock in Trier zu lassen, wo das jüngste Gericht abgehalten werden und Christus seine heiligen fünf Wunden zeigen solle. Ein Engel erscheint auch Bride am heiligen Grabe V. 1890 ff. Und die Stimme Gottes, die der Königin von dem schiffbrüchigen Orendel gesagt hat, der ihr Gatte und Herr über das heilige Grab werden solle (V. 1440 ff.), weckt auch Orendel aus dem Schlafe, als sein Heer seiner Hilfe bedarf $3697 \mathrm{ff}$. Nur einmal, wo auch ein Engel ausgereicht hätte, verfällt der Dichter auf ein andres Mittel: als Orendel, Bride und Ise in der Burg Minolts belagert werden, lässt er Maria einen Brief schreiben, den eine Turteltaube ins Lager trägt und gerade auf den Altar fallen lässt, als der Priester eine Messe singt; diesen Brief bindet dann der Führer des Heeres an seinen Speerschaft (V. 3446 ff.).

Orendels grosse Frömmigkeit wird fortwährend betont: Gleich nach der Schwertleite eilt der junge König in die Kapelle, um Marias Segen zu erbitten (182 ff.). Als die Schiffe mit Speise und Trank ausgerüstet sind, lässt ihn der Dichter die albernen Worte sagen: „Das will ich alles verzehren dem heiligen Grab zu Ehren" (237 f.). V. 266 f. ermahnt Orendel seinen Vater, dass er ja keinen Ritter zwinge ihm wider Willen zu folgen, denn wenn ein Solcher auf der Fahrt untergehe, so würde Gott sie am jüngsten Tage für dessen Seele verantwortlich machen. Bei der Aufforderung der Ritter zur Teilnahme an der Fahrt erwähnt er von seiner Brautwerbung nichts, sondern fragt nur, wer um des heiligen Grabes willen mitziehen wolle V. $291 \mathrm{f}$. $296 \mathrm{f}$. Vor der Abfahrt lässt er ein Bild von der Marter des Herrn giessen, um es in Jerusalem zu opfern (V. 323 ff.). Die Gebete Orendels werden stets ausführlich mitgeteilt, vgl. $450 \mathrm{ff}$. $564 \mathrm{ff}$. $681 \mathrm{ff}$. $1376 \mathrm{ff}$. $2696 \mathrm{ff}$. Als seine Rettung aus dem Schiffbruch berichtet wird, vergisst der Dichter nicht zu bemerken: er hâte got gar wol vor ougen 472. Den vorbeifahrenden Fischer ruft er an, er solle ihn mitnehmen um Gott und des heiligen Grabes willen V. 514 f., ähnlich 542. 917 u. s. w. Der Frau des Fischers, die ihn wegen des an ihn begangenen Unrechtes um Verzeihung bittet, erklärt er mit der Miene eines Beichtvaters: "Gott vergebe euch eure Schuld, wir sollen trachten nach seiner Huld!“ (V. 782 ff.). Als er nach Jerusalem kommt, wohnt er gleich einer Messe bei, opfert am heiligen Grabe seine Habe und verspricht, ihm mit Leib und Seele zu dienen (814 ff.). V. $1478 \mathrm{ff}$., wo Orendel erklärt, nie eines Mannes Eigen gewesen zu sein, unterlässt er nicht hinzuzufügen: ân alein gotes des vil guoten Und Sant Marîen sîner muoter. Mit seinem Gottvertrauen tröstet er auch Bride vor dem Kampfe mit Liberian V. $1750 \mathrm{ff}$. und mit Pelian V. $1890 \mathrm{ff}$. V. $1948 \mathrm{ff}$. legt er vor dem Kampfe am heiligen Grabe 
seine Kleider nieder, legt den heiligen Rock an, lässt sich eine Messe singen und nimmt das Abendmahl. In der Bekehrung der Heiden verfährt er sehr entschieden: was sich nicht taufen lassen will, wird niedergehauen, vgl. V. $2124 \mathrm{ff}$. $2825 \mathrm{ff}$. $3126 \mathrm{ff} .2581 \mathrm{ff}$. $2764 \mathrm{ff}$. $3734 \mathrm{ff}$. $3862 \mathrm{ff}$. Sogar seine Worte verbrämt er fortwährend mit Wendungen wie durch got, durch daz heilige grab, nun helfe uns got, daz vergelte dir got, wizze got, wizze Crist u. s. w., Beteuerungen, die auch die übrigen Hauptpersonen häufig genug im Munde führen. Solcher Frömmigkeit gegenüber darf aber der Priester V. 3675 ff. mit Recht sagen: wer dem Graurock beisteht, dem ist Gott und Maria hold.

Bride als Tochter Davids (V. 1601), dessen Schwert und Krone sie besitzt, als Beschützerin des heiligen Grabes und Gebieterin der Tempelherren giebt ihm an Frömmigkeit wenig nach. Gleich bei der ersten Begegnung wirft sie Orendel vor, dass er ihr die Hüter des Grabes erschlagen habe, doch er erklärt, er habe nur ihre heidnischen Knechte getötet (V. $1427 \mathrm{ff}$.). Auch sie ist eine fleissige Beterin, vgl. V. 1890 ff. 2041 ff. 2696 ff. 3264 ff. 1750 ff., wo sie sogar in fortwährendem Gebete am heiligen Grabe verweilt, ohne zu essen oder zu trinken. Gegen die Heiden kennt auch sie keine Nachsicht: als Mersilian und Stefan mit ihren Mannen ihnen entgegenfahren, erklärt sie, wenn das Heiden seien, dürfe Keiner davonkommen V. 2915 ff. Und sie weigert sich, Minolts Gattin zu werden, wenn er sich nicht taufen lasse (V. $3242 \mathrm{ff}$.). V. $2375 \mathrm{ff}$. bittet sie Gott, den gefangenen Graurock in Westval zu beschirmen, oder sie wolle den Altar zerbrechen und dem heiligen Grabe jedes Opfer entziehen. Für so unkirchliche Rede erhält sie gleich von Durian den gebührenden Verweis. Aehnlich wird auch Orendel V. 3322 ff. von Ise getadelt.

Bei Letzterem tritt die geistliche Tendenz weniger hervor: er wird am heiligen Grabe zum Herzog geschlagen; und als sie zur Burg Minolts kommen, schlägt Ise vor erst zu prüfen, ob der Türhüter auch ein Christ sei, darauf folgt das Gebet Achilles V. $3412 \mathrm{ff}$. - Auch König Ougel ermahnt seinen Sohn, Leib und Seele dem heiligen Grabe zu opfern V. $226 \mathrm{ff}$.

Zuweilen flicht der Dichter eigene Bemerkungen ähnlichen Characters ein: so kann er sich nicht enthalten, als Orendel den Rock für 30 Pfennige kauft, zu bemerken als vil was ouch der êrste schatz Dâ got unser hêr vmb verkoufet wart (V. 748 f.). V. $170 \mathrm{f}$. deutet er voraus auf die Eroberung des heiligen Grabes und die Bekehrung der Heidenschaft durch Orendel. Als Ise den verloren geglaubten Herren und seine Gattin wiedersieht, fügt der Dichter hinzu: so viel Liebes möge uns auch geschehen, des helfe 
uns der himelische degen Und welle unser aller pflegen! (V.2499f.). Und als der Priester, dem die Taube den Brief Marias überbringt, deshalb die Messe abbricht, kann er einen Tadel nicht unterdrücken: Das ist noch nie dagewesen und soll auch nie wieder vorkommen, und finge auch die Kirche zu brennen an, der Priester soll seine Messe fertig singen (V. 3658 ff.). Indem er am Ende Orendel, Bride, Ise und Achille einmütig der Welt entsagen und ins Kloster gehen lässt, setzt er seiner dichterischen Leistung die Krone auf, und mit einem frommen Wunsche für sich und seine Zuhörer schliesst er das Gedicht.

Zwischen dem burlesken, ausgelassenen Ton des Morolf, des älteren Oswald und der philisterhaften Moralität des jüngeren Oswald hält unser Dichter eine leidliche Mitte. Die geistliche Uebermalung ist weder in den übertriebenen Farben des letzteren aufgetragen, noch sucht sie durch kecke parodistische Lichter zu wirken, wie jene. Aber wirklich ernsthaft darf man sie hier auch nicht auffassen, die Absicht macht sich zu deutlich fühlbar, und um geistliche Erbauung und Erhebung der Gemüter war es dem Dichter eben nicht zu tun. Immerhin tritt der Spielmann mehr in den Hintergrund, als in den verwanten Dichtungen dieses Kreises.

Eine Gestalt, auf die sich die Züge des Spielmanns hätten übertragen lassen, wie Morolf, Alberich oder der Rabe Oswalds, eine solche Gestalt brachten dem Dichter seine Quellen nicht entgegen. So fand er nur nebenbei hie und da Gelegenheit seiner Zunft den üblichen Tribut zu bringen: in der Einfuhrung des sprachkundigen Wallers Tragemund V. 103-146, in der Behandlung, die Bride dem ungetreuen Kämmerer angedeihen lässt, indem sie ihm den Rücken schlägt, ihn an den Haaren zu Boden reisst und mit Füssen tritt (1612 ff. *) vgl. 2439 ff.), in der Gewährung von Rossen als Botenlohn $1169 \mathrm{ff}$. $3033 \mathrm{ff}$., und in der Belohnung durch Kleidungsstücke 56 ff. 2223 ff. 2331 ff. Das sind Situationen des wirklichen Lebens, die in allen Spielmannsdichtungen mit unbedentenden Variationen wiederkehren.

Dagegen ist in der ganzen Anlage des Gedichtes die spielmännische Schablone unverkennbar, und damit kommen wir zu der zweiten Hauptleistung des Ueberarbeiters.

Aus der in seiner Quelle irgendwie (vielleicht wie in andern Heimkehrsagen durch einen Traum) motivierten Ostfahrt Orendels und seiner Trennung von der Gattin macht er eine Orientfahrt des Königs Orendel von Trier zur Gewinnung einer Braut im Morgenlande. Das ist der bekannte, der gesammten Spielmanns-

*) Diese möglicher Weise schon in der Vorlage, vgl. S. LXX. XCVI. 
dichtung gemeinsame Brautfahrtvorwurf, mit dem die Richtung auf das Morgenland und die Heidenbekehrung auf das Engste zusammenhängt, während die Localisierung Brides in Jerusalem und Orendels in Trier, sowie dessen Kampf um das heilige Grab erst aus der Einflechtung einer Legende zu erklären ist. Den Schiffbruch Orendels bis zur Anrufung Ises nahm der Ueberarbeiter aus seiner Vorlage unverändert auf. Das Misstrauen aber, mit dem Ise im alten Gedichte dem nackten Fremdling begegnet, der sich ihm als den schiffbrüchigen König Orendel zu erkennen gegeben - dies berechtigte Misstrauen bauscht er in alberner Uebertreibung auf: Ise hält den nackt und hilflos in öder Wildnis Gestrandeten für einen Räuber und Dieb! Und statt seinen Namen zu nennen, muss ihn Orendel thörichter Weise verschweigen und sich für einen gescheiterten Fischer ausgeben, aus dem einfachen Grunde, weil in dem Fischzuge Orendels, wobei sich der graue Rock - in Anknüpfung an die Vorgeschichte - im Fischmagen wiederfindet, ein Wunder vorgeführt werden soll. Dieser wunderbare Fischzug erklärt auch die Veränderung, dass Orendel von Ise nicht - wie in der Quelle die Hälfte seines Gewandes, sondern den ganzen Rock erhält. Während aber in der Vorlage Rock, Ross und Schild zusammengehören, riss sie der Spielmann mit seiner Vorliebe für Wiederholung ähnlicher Motive auseinander, unterdrückte deshalb an dieser Stelle den Rossfang Ises und lässt seinem Helden Ross und Schild erst später durch einen Heiden Mercian zu Teil werden, wiederum gegen das Gelöbnis der Dienstbarkeit; dabei bildet er die Scene von der Bändigung des Rosses dem Rossfang Ises nach, wie oben gezeigt wurde. Wie durch diese willkürliche Spaltung die einzelnen Züge ganz unverständlich geworden sind, ist ebenfalls früher ausfuhrlich dargelegt worden. Als Orendel eine Reihe von Freiern besiegt hat, sendet ihm Bride einen Boten, ihm ihre Minne zu entbieten. Der Brautfahrer Orendel wäre ja damit am Ziele seiner Wünsche, könnte frisch zugreifen, und das Lied wäre glücklich zu Ende. Statt dessen speist er den Boten mit dürren Worten ab und verleugnet sich. Dasselbe alberne Schauspiel wiederholt sich dann nach jedem der Riesenkämpfe und geht sogar so weit, dass der vorher so minneeifrige Orendel das ihm angebotene Beilager ausschlägt und ein Schwert zwischen sich und die Jungfrau legt. Wie dieser kindische Widersinn nur aus dem tiefen Grundgedanken der alten Dichtung zu begreifen ist, wurde S. XCV f. auseinandergesetzt. Während ferner in der Vorlage ein neidischer Freier der Königin zum Vorwurf macht, dass sie einen gemeinen Mann in knechtischer Tracht küsse, muss hier nach allem Vorangegangenen Mercian die Königin schelten, weil sie seinen Knecht küsse. Aus dem treff- 
lichen Schwerte, das Bride dem Gatten reicht, und das jedenfalls sein eigenes, seiner Hand allein vorbehaltenes war, macht der Bearbeiter das Schwert Davids. Dass endlich im dritten Kampfe, als Bride die eigenen Mannen anfallen will, Orendel sich plötzlich pathetisch zu erkennen gibt, wirkt in unserer Bearbeitung einfach lächerlich: was soll damit entschieden werden? wie dieser hergelaufene Ankömmling heisst, kann den Freiern herzlich gleichgiltig sein. Dennoch sind sie tief erschrocken und huldigen ihm augenblicklich. Für dieses sinnlose Betragen stand dem Spielmann eben kein Motiv zu Gebote. Aber das mehr als überraschende Benehmen Brides, die, obwol von einer glänzenden Freierschaar umworben, für den unbekannten, dürftig gekleideten Fremden so energisch ins Zeug geht und sich ihm geradezu an den Hals wirft, während er, der sie doch gern besitzen möchte, eine jüngferliche Sprödigkeit herauskehrt, die sie nur noch zudringlicher macht - dies Benehmen hat der Spielmann doch wenigstens durch ein bestimmendes Motiv zu mildern gesucht: die Stimme Gottes hat ihr verkündigt, dass König Orendel von Trier ihr Gatte werden solle und bestimmt sei das heilige Grab zu gewinnen. Das stimmt aber vortrefflich zu seiner ganzen geistlichen Neigung und seiner Motivierungsweise überhaupt, die in ihrer gedankenlosen Bequemlichkeit am Liebsten Alles dem Himmel und seinen woltätigen Heiligen in die Schuhe schiebt. Unter seinen groben Händen ist also Alles, was im alten Gedichte edel und tief begründet war, albern und unverständlich geworden, die Gestalt Orendels fast zu einer Fratze und Bride - im besten Falle! - zu einem Character, der nicht nach eigener Willensmeinung, sondern unter der Einwirkung einer himmlischen Bestimmung handelt.

Was der Ueberarbeiter an neuen Zügen dem Gang seiner Quelle eingefügt, hängt fast durchweg mit derselben geistlichen Tendenz zusammen und ist vorhin unter diesem Gesichtspunkt erörtert worden. Daher erklärt sich auch, dass aus den Freiern und ihren Mannen zum grössten Teile Heiden gemacht sind, die von Orendel erbarmungslos niedergemetzelt werden. Sonst beschränken sich die Zutaten auf den ganz physiognomielosen Seekampf mit dem Heidenkönig Pelian V. 401 ff. die Schachspielscene zwischen Mercian und Sudan, die in der Volksepik traditionell ist (vgl. Vogt, SM. S. CXXI), die Schilderung kunstvoller Schmiedearbeit (vgl. Anmkg. zu V. 973), die Berufung der Tempelherren durch Bride (allerdings wieder auf himmlische Weisung) V. 1910 ff.*) und die Gattin, die Ise beigegeben ist (vgl. unten).

*) In dem Hohn der Tempelherren V. 1975 ff., Orendel sei wol aus dem Kloster entronnen, steckt gewiss ein echtes Stück der alten Dichtung. 
Den Schluss des alten Gedichtes hat der Ueberarbeiter, wie schon auseinandergesetzt wurde, gröblich verschoben. Nach der Vorlage ruft Orendel seinen Woltäter Ise an den Hof, Dieser kommt in seinem grauen Rock und kehrt reich belohnt nach Haus zurück. Der Spielmann wollte aber jetzt auch Ise mit einer grösseren Rolle bedenken und brauchte eine Anknüpfung, um seinen Faden weiter fortzuspinnen. In seiner plumpen Weise nahm er deshalb die $\mathrm{Be}$ rufung Ises durch Orendel von ihrem richtigen Platze und setzte sie erst nach Ises Rückkehr ein, um nun flott weiter erzäblen zu können. Dafür liess er an jener Stelle Ise von selbst erscheinen und seinen Knecht zurückfordern: das ist aber ein Missverständnis, denn Ise hat nach der Vorlage dazu nicht das mindeste Recht. Und so ergibt sich denn der grobe Widerspruch, dass Orendel, nachdem er eben sein Verhältnis gelöst hat, sich ihm immer noch verpflichtet fühlt und ihn abermals beruft, als wäre nichts geschehen. So hat die gedankenlose Sudelei der Bearbeitung Verwirrung über Verwirrung angerichtet.

Nunmehr folgt ein grösseres Stück, in dem der Bearbeiter ganz auf eigenen Füssen steht. Ise wird zum Herzog geschlagen. Jetzt sehen wir auch, warum Ise V. $590 \mathrm{ff}$. als ein Beherrscher von 800 Fischern und Besitzer einer herrlichen Burg bezeichnet wird:*) wer zur Herzogswürde auserkoren war, durfte kein gemeiner Mann sein, der in dïrftiger Hütte haust. Um seine neue Würde gleich zu bestätigen, gebietet Ise eine Heerfahrt nach Westval, bei der Orendel und später auch Bride gefangen werden, natürlich nur, um wieder durch himmlische Hilfe befreit zu werden (vgl. S. CIV). Darauf senden die babilonischen Könige Elin und Durian den Herzog Daniel mit Fehdebriefen zu Orendel, der den Boten mit zwei mächtigen Faustschlägen abfertigt gegen alles Völkerrecht. Orendel besiegt darauf Durian im Zweikampf, wiederum mit himmlischer Unterstiutzung, und die Heiden unterwerfen sich sammt und sonders. Auch das sind wieder ganz physiognomielose Kämpfe ohne das geringste poetische Interesse, bei denen es sich in erster Linie darum handelt, möglichst grosse Massen von Heiden zum Christentume zu bekehren. Aber der heilige graue Rock muss nun vor Allem nach Trier gebracht werden. Orendeln erscheint also der übliche Engel fataler Weise gerade, als er mit Bride das Lager teilen will (V. $2844 \mathrm{ff}$.) - der ihm verkündet, dass Trier von Heiden belagert sei. Sie rüsten sich zur Abfahrt und übergeben Ise das heilige Grab. Doch Dieser lehnt es ab, weshalb sie es dem Schutze zweier Her-

*) Der grobe sich daraus ergebende Widerspruch zu der „Klause“ ist oben S. LXXIII besprochen worden. 
zöge anvertrauen, die es an die Heiden verraten. Unterwegs stossen Mersilian und Stefan zu ihnen, Ises mächtige Söhne, die wiederum zu dem „armen Fischer" gar nicht passen. An dieser Stelle verwertet der Bearbeiter den Rossfang Ises aus dem alten Gedicht mit der albernen Motivierung, dass Bride Orendel auffordert, ihren Mannen Rosse und Gewänder zu kaufen, damit sie die Blicke der Frauen auf sich lenken (V. 2984)! Dann zieht die ganze Schaar auf dem bekannten Kreuzfahrerwege nach Metz und Trier, wo die Belagerer (die hier sogar noch Heiden sind, damit sie nachiher zu grösserer Erbaulichkeit wieder getauft werden können) im Bussgewand ihm reumütig entgegenziehen. Ein Engel befiehlt, den heiligen Rock in Trier zu belassen, wo er in einem Steinsarg verwahrt wird. Damit hat der Bearbeiter sein Hauptziel erreicht. Diese ganze Partie trägt aber durchaus den Stempel seiner kläglichen Erfindungsarmut und stümperhaften Darstellungsweise. Der immer wieder betonte Gegensatz zwischen Christen und Heiden, das fortwährend wiederholte Eingreifen des Himmels, diese aneinandergereihten Kämpfe, deren ermüdende Langeweile nicht durch eine lebhaftere Schilderung, ein anschaulicheres Bild, eine poetische Wendung unterbrochen wird - das Alles zeigt hinlänglich, wie ein solcher Stümper arbeitete, wo ihm keine ausgefuhrte Quelle zur Seite stand.

Wie die Dichter des Morolf und des Rother nimmt aber auch unser Bearbeiter jetzt den abgesponnenen Faden von Neuem auf und trägt die Geschichte nochmals in abweichender Gestalt vor. Und fuir diese Fortsetzung stand ihm, wie wir sahen, eine zweite treffliche Vorlage zu Gebote. Den Anlass zur Rückkehr nach Jerusalem gibt ein Traum Brides, Jerusalem sei wieder in der Heiden Gewalt. Ich möchte glauben, dass darin ein echter Bestandteil der alten Dichtung steckt, wo wahrscheinlich Orendels Ostfahrt, wie in vielen verwanten Sagen, durch einen Traum motiviert war. Im Uebrigen besteht des Bearbeiters Thätigkeit hier eigentlich nur in der grenzenlosen Verwirrung, durch die er das schöne Gefüge seiner vortrefflichen Quelle zerstört hat (vgl. oben S. LXXVI f.). Ausserdem streute er eine Anzahl geistlicher Brocken ein, die bereits näher bezeichnet wurden, und liess auch Ise an der Handlung durchweg teilnehmen, ohne dass aber Dieser über die Rolle eines Statisten hinauszukommen vermöchte: V. 3722 schlägt er dem Pförtner den Kopf ab, 3752 zündet er die Burg an, V. 3740 lässt ihn der Ueberarbeiter statt Orendels, wie es natürlich in der Vorlage lautete, den Nebenbuhler erschlagen. Dass Orendel und Ise ihr Heer verborgen halten und allein nach Minolts Burg aufbrechen (V. $3355 \mathrm{ff}$.) erinnert an Morolf, Rother, Oswald v. A. Die Herausführung Brides aus der Burg 3368-3401 ist eine ungeschickte Scene, die auch 
eigentlich nur V. 3225-40. 3308-21 wiederbolt. Die Waffnung Brides (V. 3825 ff.) ist der Ausrüstung Orendels und Ises bei Achille (V. 3494 ff.) nachgebildet. Der Schlaftrunk, von dem Wolfhart berauscht erschlagen wird, ist wol aus der Geschichte der Judith entnommen. Darauf folgt die Zurückgewinnung des heiligen Grabes und allgemeine Heidentaufe; der mönchische Schluss stimint zu den andern Spielmannsdichtungen.

Die von dem Bearbeiter neu eingeführten Persönlichkeiten wie Herodes, Schiltwin, Alban, Pelian sind blutlose Schemen ohne die allergeringste individuelle Färbung. Ein gewisser Ansatz zu einer Characteristik zeigt sich nur in der wiederholt hervortretenden Neigung zu paarweiser Gegenüberstellung von Personen, wobei stets derselbe Gegensatz zum Ausdruck kommt. Meister Ise ist dem nackten Fremdling nicht übel gesinnt, er nimmt ihn mitleidig auf, seine Frau aber will, dass er ihn in das Meer werfe (614f.), erst bei seinem Abschied bittet sie um Verzeihung für ihr unbilliges Benehmen. Aehnlich ist das Verhältnis bei Mercian und Sudan. Ersterer überlässt dem Graurock gern sein Ross und warnt ihn vor seiner unbändigen Natur, er sollte es lieber an einen Stein führen, um ohne Schaden hinaufzusteigen (956 ff.); Dieser aber schmäht ihn mit hochfahrenden Worten um seiner knechtischen Kleidung willen und trachtet ihm nach dem Leben. Derselbe Gegensatz kehrt auch bei Warmund und Berwin wieder: Jener will unwillig dem Rossfang Ises Einhalt tun, Dieser hält ihn bedachtsam zurück (3014 ff.). Weniger deutlich tritt dies Verhältnis bei Elin und Durian hervor, gar nicht mehr bei den Brüderpaaren Mersilian und Stefan und den zur Hut des Grabes bestellten Herzögen. Dagegen stehen sich in Minolt und Achille; in Wolfhart und Daniel wieder begehrliche Selbstsucht und unbestechliche Mannentreue gegenüber. Der Waller Tragemund ist der bekannte Typus der fahrenden Leute. So geht auch die Characteristik nirgends über Hergebrachtes oder Typisches hinaus, und wo sich eine scharf umrissene und folgerecht gezeichnete Persönlichkeit wie Orendel, Bride, Ise, der Buhle oder der Pförtner durch die Quellen wirklich darbot, da hat der täppische Ueberarbeiter mit seiner ganz abweichenden, durch die Veränderung des Grundplanes bedingten Motivierung oder mit der Alles ausgleichenden Langeweile seines Legendentones die Linien nur verwischt und verdunkelt.

Von höfischer Bildung ist unser Spielmann noch kaum gestreift worden: zwar sind ihm die ritterlichen Kampfspiele nicht fremd, wie die Scene in Brides Burghof lehrt, sogar der Begriff des Turniers ist ihm geläufig (V. 2324); auch das vornehmste Spiel der höfischen Kreise, das Schachspiel erwähnt er (V. 901) und bedient sich sogar 
einer Anzahl höfischer Wörter: banier 1945, sablar 1116, turnier 2324, rabît 1276. 2094, daneben sehr häufig kemenâte, galîe, die freilich in allen Volksepen vorkommen.*) Aber der Frauendienst spielt im Gedichte noch keine Rolle: hier ist noch, wie in alter Zeit, der Mann der Begehrenswerte, zu dem die Frau dienend aufschaut. Das Wort minne wird nur in sinnlicher Bedeutung verwant (1807. 1827. 3872), ebenso liebe 3227 und huld 3806, gleichbedeutend mit buolschaft 2429. Von höfischer Etikette findet sich noch nicht die leiseste Spur. Die Form der Anrede ist noch ganz ungeregelt.. Im Allgemeinen gilt ${ } \mathrm{Du}^{4}$ als Anrede, ob nun ein Höherer zu einem Niederen spricht oder umgekehrt, oft genug wechseln "du" und "ihr" in demselben Satze. So sagen z. B. Ise und seine Gattin "Ihr" zu einander 606. 619, aber 659 „du“. Orendel ihrzt seinen Vater 195, bekommt aber "du" zurück. Bride nennt Orendel meist $n$ ihr", aber 1509 f. 1579.1637 ff. 1832. 2083 f. u. s. w. duzt sie ihn. Sogar der Kämmerer redet Bride einmal mit ${ }_{\eta} \mathrm{du}^{*}$ an $1617 \mathrm{ff}$., ebenso Durian (2388) und Alban 2442. Auch Princian duzt Minolt 3248 ff. 3577 ff., Durian Wolfhart 3792 ff. Beispiele für Wechsel von ,du“ und ,ihr“ in einem Atem sind 530. 535. 941. 942. 947. 948. 1439. 1452. 2462. 2463. 3548. 3551 u. s. w. So geht Alles bunt durcheinander. Das höfliche Willkommenheissen bei der Ankunft, das meist erwähnte Urlaubnehmen beim Abschied findet sich in anderen Spielmannsgedichten auch. Gemütsbewegungen kommen ungehemmt zum Ausbruch: Orendel rauft sich vor Jammer das Haar aus (669), Bride bricht, als sie von Orendels Gefangennahme erfährt, in heisse Thränen aus und droht sogar dem Himmel (2373 ff.). An kostbaren Stoffen kennt das Gedicht nur Pheller, Seide und Zobel, an Edelsteinen nur Jachant, Smaragd und Rubin.

$\mathrm{Zu}$ dieser kaum merklichen Beeinflussung durch höfisches Wesen stimmt der niedrige Bildungsgrad des Bearbeiters, wie er in der unwürdigen Behandlung des Kämmerers durch Bride (1614 ff.), Mercians und Daniels durch Orendel (1486 ff. $2611 \mathrm{ff}$.), sowie in der wiederholten Prügelei der Albanscene 2439 ff. 2480 ff. hervortritt. Dagegen hat uns das Gedicht eine Reihe von altertümlichen epischen Zügen bewahrt, die ich - und zwar, der besseren Uebersicht wegen, auch soweit sie der älteren Grundlage angehören hier im Zusammenhang aufführen will. Die Mannen, vom Fürsten zur Beratung berufen, stellen sich ringförmig auf (V. 288). Wer sich an der Expedition beteiligen will, legt zum Zeichen seiner Mit-

*) Andere Fremdworter wie capelle, messe, münster, evangellum stammen natïrlich aus der Sprache der Geistlichkeit.

Orendel. 
wirkung goldene Sporen an (320). Beim Aufbruch werden Gesänge angestimmt (344 u. Anmkg.). Mut und Tapferkeit prägen sich in Blick und Bau der Schultern aus (1134. 1181 u. Anmkg.). Als Symbol der unberührten Jungfräulichkeit gilt das zwischen Mann und Weib hegende Schwert (1818 u. Anmkg.). Orendel kämpft allein gegen ganze Heere (1371 ff. $1660 \mathrm{ff}$. $2035 \mathrm{ff}$.). Statt zweier Heere kämpfen nur zwei ausgewählte Helden (2691 u. Anmkg.). Bride sitzt wie ein Mann zu Pferde mit einer Stange bewaffnet (2062 ff.). Gold wird in Schilden zugemessen (2195 u. Anmkg.). Einige andere, auf Ausrïstung oder kriegerische Sitte weisende altertümliche Zïge sind in den Anmerkungen nachgewiesen.

Was die Darstellung schliesslich angeht, so lässt sich diese mit wenigen Worten abtun. Sie bewegt sich durchaus in den feststehenden Formeln der Spielmannspoesie und liebt auch Wiederholungen grösserer Partieen (485 ff. $=670$ ff. 880 ff. 2133 ff.; 840 ff. $=1102$ fl. 1426 ff. 1766 ff. 2563 ff. 2744 ff. 969 ff. $=$ 1038 ff. 1642 ff. 1964 ff. 2055 ff. 2713 ff. 3832 ff.; 1394 ff. $=$ 1672 ff. 2845 ff.; 2567 ff. $=2580$ ff. 2748 ff. 2760 ff.; 3225 ff. $=3308$ ff. 3373 ff. u. s. w.). Der spielmännische Character der Darstellung tritt besonders bezeichnend in den gelegentlichen Bitten um einen Trunk hervor (vgl. Anmkg. z. 2791), womit vermutlich auch Pausen, wie sie V. $375 \mathrm{f}$. (Nun râtent alle in disem ringe Wie wir si von dannen bringen, vgl. 1141. 2361. 2476) angedeutet werden, ausgefüllt wurden. Wie die Manier der Spielmannspoesie in den durchgehends gebrauchten Reimformeln hervortritt, darüber geben die Anmerkungen nähere Auskunft; wie sie sonst in typischen Zahlenangaben, in stehenden Beiwörtern, in den Anreden an die Zuhörer, in Wahrheitsbeteuerungen, Quellenberufungen, epischen Vorausdeutungen, im Wortschatz u. dergl. sich geltend macht, braucht hier nicht weiter ausgeführt zu werden. Die Technik der Spielleute ist in allem Wesentlichen eine, jedenfalls unter allen Arten schulmässiger Technik, welche wir kennen, diejenige, die dem Einzelnen der sie ausủbt, am Wenigsten selbständige Bewegung verstattet. Eine Betrachtung eines einzelnen Gedichtes nach dieser Seite wäre also wertlos, sobald sie nicht im Zusammenhange mit den andern Epen dieses Kreises geführt wird. Aber auch eine erschöpfende Darstellung aller dieser traditionellen Kunstmittel, welche hier zu weit führen würde, könnte doch nur bestätigen, was Fr. Vogt in seiner Behandlung der Spielmannschablone (Salm. u. Mor. S. CXXXVIII f.) bereits hinreichend festgestellt hat. Erwähnt sei nur noch, dass von der Reimbrechung in unserm Gedichte ausgedehnter Gebrauch gemacht wird, wofür fast jede Seite Beispiele bietet, und dass die Epitheta, die in der späteren Spielmannspoesie 
nur noch als Flitter gelten und in der widersinnigsten Weise durcheinander gebraucht werden (vgl. Jänicke zu Wolfdietrich D VI, $66,2)$, hier noch durchaus nach ihrem vollen Bedeutungsinhalt empfunden werden. Die beginnende Erstarrung im Formelhaften zeigt sich nur gelegentlich in den Anreden Mercians und Durians an Orendel (1090. 2744), die zu der feindlichen Situation nicht passen. Im Uebrigen entbehrt auch die Darstellung jeglichen Reizes. Wo einmal ein sinniger Zug, eine poetische Wendung hervortrat, da konnten wir sie auf die benutzten Vorlagen zurückführen oder aber als formelhaft nachweisen, wofür die Anmerkungen zahlreiche Belege bieten. Sonst unterbricht jedoch kein Bild, keine lebhaftere oder individueller gefärbte Ausdrucksweise die öde Einförmigkeit der Erzählungsweise.

Nach alledem kann unser Urteil über die Leistung des Ueberarbeiters nichts weniger als günstig ausfallen. Dem hohen dichterischen Werte seiner Vorlagen steht er verständnislos gegenüber; die logische Entwicklung, die Feinheit der Characterzeichnung, die runde Geschlossenheit des Aufbaues - Alles zerfällt ihm unter den Händen. Die hoheitsvolle Heldensage modelt er zu einer trockenen Legende um, und selbst ein gesunder Spielmannshumor vermag nirgends durchzubrechen. Wo er Eigenes bringt, greift er nur zu Typischem oder zu überliefertem Fabelgut: durch nichts vermag er uns in seiner langweiligen Physiognomielosigkeit für den Verlust seiner trefflichen Quellen zu entschädigen. 
